\title{
HUBUNGAN GANGGUAN TIDUR PADA PEKERJA SHIFT DENGAN KEJADIAN KECELAKAAN KERJA DI TERMINAL PETIKEMAS
}

\section{RELATIONS BETWEEN SLEEP DISTURBANCE ON SHIFT WORKERS WITH WORK ACCIDENT AT CARGO TERMINAL}

\author{
Ayu Wanda Saraswati, Indriati Paskarini \\ Departemen Keselamatan dan Kesehatan Kerja \\ Fakultas Kesehatan Masyarakat, Universitas Airlangga \\ E-mail: ayu.wanda-13@fkm.unair.ac.id
}

\begin{abstract}
Working at night can causes some impacts on shift worker's life, such as their health, safety and also social life. Sleep disturbance is one of the impacts from working at night, and it will influenced their health and safety, as well as the social life of shift workers. This condition will increased the risk of work accident on night shift. The purpose of this research is to study the relationship between sleep disturbance and work accident at cargo handling terminal. This research is categorized as case-control research, and using primary data that retrieved by giving questionnaires to the shift workers. The result of statistical test which using Chi-Square test shows that there is a relationship between sleep disturbance in shift workers and the work accident at cargo handling terminal $(0.0015<0.005)$. The relationship value between this two variable is 0.322 . The effort that can be done to lower the sleep disturbance is doing a good combination of adequate hours of sleep and proper consumption of caffeine.
\end{abstract}

Keywords: accident, loading and dismantling container port, night work, shift worker, sleep disturbance

\begin{abstract}
ABSTRAK
Bekerja pada malam hari dapat menyebabkan dampak pada kesehatan dan keselamatan serta kehidupan sosial para pekerja shift. Gangguan tidur merupakan salah satu dari bahaya akibat bekerja pada malam hari, dan akan memberikan dampak pada kesehatan, keselamatan, serta kehidupan sosial para pekerja shift. Hal ini mengakibatkan bertambahnya risiko kecelakaan kerja pada shift malam. Tujuan penelitian ini adalah mempelajari hubungan antara gangguan tidur dengan kecelakaan kerja di terminal bongkar-muat petikemas. Penelitian ini menggunakan rancang-bangun case-control dan pengambilan data primer menggunakan kuesioner untuk para pekerja shift. Hasil uji statistika menggunakan Uji ChiSquare menunjukkan bahwa terdapat hubungan gangguan tidur pada pekerja shift dengan kejadian kecelakaan kerja pada terminal bongkar-muat petikemas $(0,0015<0,005)$. Adapun besar hubungan antar keduanya adalah 0,322 . Hal yang dapat dilakukan untuk menurunkan gangguan tidur adalah kombinasi antara jam tidur yang adekuat dan konsumsi kafein yang tidak berlebihan.
\end{abstract}

Kata kunci: bekerja malam, gangguan tidur, kecelakaan kerja, pekerja shift, terminal bongkar-muat petikemas

\section{PENDAHULUAN}

Shift kerja adalah sebuah sistem tentang pengaturan jam kerja, pekerja yang bersangkutan dapat saling menggantikan satu sama lain pada bidang yang sama setelah periode waktu tertentu yang telah disepakati sebelumnya, dan bertujuan untuk tetap melakukan proses produksi supaya tetap berlangsung selama 24 jam. Periode waktu yang disepakati bersama dengan pihak manajemen biasanya memiliki durasi waktu 8 jam atau 12 jam per shift kerja.
Perubahan sosial dan perubahan gaya hidup yang menjadi aktif selama 24 jam merupakan salah satu alasan dari munculnya tren melakukan pekerjaan secara shift (Health and Safety Authority, 2012). Pekerjaan shift yang pada awalnya diberlakukan untuk pekerjaan yang bersifat melayani publik, dewasa ini para pelaku industri juga mulai menerapkan pengaturan jam kerja seperti ini demi memenuhi permintaan dari konsumen.

Health and Safety Authority (2012) memperkirakan di Irlandia ada sekitar 270.000 
pekerja dari 1,8 juta pekerja telah melakukan pekerjaan secara shift dan pekerjaan malam. Jumlah ini diramalkan akan terus mengalami kenaikan untuk tahun-tahun selanjutnya. Hal ini sejalan dengan pernyataan Labour Force Survey pada tahun 2005 yang menegaskan bahwa pekerjaan yang dilakukan secara shift di Inggris mengalami kenaikan dalam 25 tahun terakhir, dengan jumlah terbanyak ada pada tahun 2000 yakni sekitar 15\% dari populasi pekerja telah bekerja secara shift selama hampir seluruh waktu.

Bekerja secara shift, terutama pada malam hari, nyatanya memberikan dampak pada kinerja dari tubuh pekerja itu sendiri. Tubuh manusia memiliki ritme tersendiri, yang dinamakan dengan ritme sirkadian. Ritme sirkadian ini berfungsi untuk mengatur proses kerja dari tubuh manusia, dan ritme ini sangat peka dengan keberadaan cahaya. Jika cahaya yang diterima tubuh menurun, maka ritme sirkadian akan memerintahkan tubuh untuk memperlambat proses kerjanya, begitu pula sebaliknya. Sesungguhnya bekerja pada malam hari yang notabene minim pencahayaan telah melawan ritme sirkadian dari tubuh pekerja itu sendiri.

Penelitian yang dilakukan oleh Smith et al. pada tahun 1994 menyimpulkan bahwa risiko kecelakaan kerja pada shift sore dan shift malam lebih tinggi jika dibandingkan dengan shift pagi. Adapun risiko kecelakaan kerja pada shift sore menjadi lebih tinggi sekitar 15\%, sedangkan pada shift malam bahkan menjadi 23\%. Peningkatan risiko kecelakaan kerja ini juga didapatkan National Longitudinal Survey of Youth dalam hasil studi yang dipublikasikan oleh Dembe et al (2006), yang menyimpulkan bahwa pekerja pada shift sore dan shift malam memiliki risiko masing-masing sebesar $43 \%$ dan $30 \%$.

Peraturan Menteri Perhubungan Republik Indonesia nomor 51 tahun 2015 tentang Penyelenggaraan Pelabuhan Laut mendefinisikan pelabuhan sebagai tempat yang terdiri dari daratan dan perairan di sekitarnya, dengan beberapa batas sebagai tempat kegiatan pemerintah dan ekonomi, dan salah satu layanan yang disediakan untuk mendukung kegiatan ekonomi adalah melakukan bongkar muat barang. Pelabuhan Tanjung Perak Surabaya pada tahun 2009 menerima sebanyak 58.778.000 ton pelayanan petikemas (Organisation for Economic Co-Operation and Development, 2012). Banyaknya pelayanan petikemas yang harus dilakukan, nyatanya tidak berbanding lurus dengan waktu bersandar yang diberikan untuk setiap kapal. Untuk itu, pelabuhan dalam hal ini terminal petikemas mau tidak mau harus tetap beroperasi selama 24 jam untuk menyelesaikan pelayanan bongkar muat barang.

Steenken et al (2004) menjelaskan bahwa setelah kapal yang berisi petikemas mendekat ke dermaga dan melempar jangkar untuk mempertahankan posisinya, Container Crane (CC) akan menjalankan lengan trolleynya untuk mengaitkan adaptor pada sisi-sisi petikemas, dan kemudian petikemas akan diangkat. Selanjutnya, petikemas tersebut akan diletakkan di atas chassis truk untuk selanjutnya diletakkan di lapangan penyimpanan. Setelah menyelesaikan proses administrasi dan dokumentasi, maka selanjutnya petikemas akan diangkat menggunakan Rubber Tyres Gantry (RTG) untuk selanjutnya diletakkan pada truk yang akan membawa petikemas tersebut sesuai dengan tujuan masing-masing.

United Kingdom Departement of Transport (2005) menuliskan bahwa rasio kecelakaan kerja pada pekerja yang bekerja di sektor pelabuhan mencapai 1.0 per 100 pekerja. Hal ini diperbaharui oleh Health and Safety Authority yang menuliskan bahwa pada tahun 2012 hingga pertengahan 2013, rasio kejadian kecelakaan kerja sebesar 114,4 per 100.000 pekerja di Inggris.

Salminen (2010) menyatakan dalam hasil penelitiannya bahwa pada negara yang berkembang, risiko kecelakaan pada shift pagi lebih kecil jika dibandingkan dengan shift malam. Namun, jika membandingkan angka kejadian kecelakaan kerjanya, maka didapatkan bahwa angka kejadian kecelakaan kerja pada shift malam lebih sedikit jika dibandingkan dengan shift pagi. Hal ini lantaran kurangnya keberadaan supervisor keselamatan pada saat shift malam tengah berlangsung di tempat kerja. Hal ini sejalan dengan penelitian yang dilakukan oleh Anggraeni di PT. Terminal Petikemas Surabaya pada tahun 2014 yang menyebutkan bahwa lemahnya pengawasan oleh manajemen merupakan salah satu faktor penyebab dari kejadian kecelakaan kerja.

Health and Safety Authority (2015) menjelaskan macam-macam bahaya utama yang ada pada dermaga dan pelabuhan, termasuk juga terminal petikemas. Macam-macam bahaya itu yakni jatuh dari ketinggian, kejatuhan benda, kelelahan, lifting equipment, api/listrik, substansi berbahaya, peralatan dan kendaraan bergerak, jangkar, musculoskeletal disorders (MSDs), kebisingan, terpeleset dan tersandung, bahaya dari lingkungan, dan yang terakhir adalah shift kerja/bekerja pada malam hari (night work). 
Shift kerja/bekerja pada malam hari (night work) dapat dikategorikan menjadi bahaya karena dapat memberikan efek pada para pekerja. Adapun dua efek utama yang ditimbulkan adalah efek pada kesehatan dan keselamatan serta efek pada kehidupan sosial dan keluarga (Australian Manufactur Workers' Association, 2009).

Efek kesehatan dan keselamatan yang dapat memapar pekerja shift antara lain perubahan pada ritme natural dari tubuh, masalah atau gangguan pada tidur (sulit tidur), peningkatan kelelahan (baik secara mental maupun fisik), gangguan pada pola makan, dan sebagainya. Adapun beberapa contoh efek pada kehidupan sosial dan keluarga yakni isolasi dari berbagai aktivitas yang dapat dilakukan bersama keluarga, komunikasi dengan teman dan keluarga menjadi menurun, dan berkurangnya kesempatan untuk mendapatkan olahraga dan pendidikan.

Health and Safety Authority (2012) menjelaskan bahwa ketika kebutuhan tidur seseorang tidak dapat terpenuhi dengan baik, maka hal itu akan menimbulkan terjadinya kelelahan, dan selanjutnya dapat mengarah pada kejadian kecelakaan kerja. Hal ini diakibatkan oleh keadaan tubuh dan lingkungan kerja yang tidak selaras. Tidak terpenuhinya kebutuhan tidur tersebut akan membuat pekerja shift merasakan keinginan untuk tidur yang sangat besar pada saat sedang bekerja. Tujuan penelitian ini adalah untuk mengetahui gangguan tidur yang dialami para pekerja shift, mengetahui kejadian kecelakaan kerja pada malam hari, serta mempelajari hubungan antara gangguan tidur yang dialami pekerja shift dengan kejadian kecelakaan kerja pada malam hari.

\section{METODE}

Rancang bangun penelitian ini merupakan penelitian casecontrol, dengan membagi subjek penelitian menjadi dua kelompok, yakni kelompok kasus dan kontrol. Penelitian ini merupakan penelitian analitik, karena penelitian ini tidak menggambarkan keseluruhan populasi. Peneliti tidak melakukan perlakuan apapun terhadap subjek penelitian, sehingga penelitian ini masuk ke dalam jenis penelitian observasional. Penelitian ini termasuk dalam jenis penelitian lapangan karena penelitian dilakukan langsung pada tempat subjek berada.

Lokasi penelitian dilakukan pada sebuah terminal bongkar-muat petikemas yang terletak di Surabaya. Waktu untuk menyusun proposal penelitian ini dimulai pada November 2016 hingga April 2017. Pengambilan data pada tempat penelitian dimulai pada Mei 2017.

Populasi dari penelitian ini terbagi menjadi dua kelompok. Kelompok pertama yang merupakan kelompok kasus memiliki populasi berupa seluruh pekerja shift yang mengalami kecelakaan kerja pada saat bekerja pada malam hari, sedangkan kelompok kedua yang merupakan kelompok kontrol memiliki populasi yaitu seluruh pekerja shift yang tidak mengalami kecelakaan kerja pada saat bekerja pada malam hari. Adapun cara pengambilan sampel menggunakan metode simple random sampling dan menghasilkan sampel penelitian sebanyak 41 orang untuk setiap kelompok.

Variabel penelitian ini terbagi menjadi dua jenis, yakni variabel dependen atau variabel terikat dan variabel independen atau variabel bebas. Variabel dependen pada penelitian ini adalah kecelakaan kerja yang dialami oleh pekerja shift yang bekerja pada malam hari, sedangkan variabel independennya adalah gangguan tidur yang dialami oleh para pekerja shift.

Cara pengumpulan data adalah peneliti menggunakan kuesioner yang akan diisi oleh pekerja shift. Penelitian ini menggunakan data primer yang didapatkan dari hasil kuesioner yang diisi oleh subjek penelitian. Adapun analisis data yang akan digunakan adalah menggunakan metode uji chi-square untuk melihat hubungan antara variabel dependen dengan variabel independen.

\section{HASIL}

\section{Gambaran Umum Terminal Bongkar-Muat Petikemas}

Terminal bongkar-muat petikemas ini merupakan terminal petikemas bertaraf internasional pertama yang ada di Surabaya, dan melayani proses bongkar-muat bagi pelaku usaha di wilayah Indonesia Timur, baik dengan tujuan domestik maupun internasional. Pada tahun 1992, perusahaan ini masih bernama Unit Terminal Petikemas (UPTK). Tujuh tahun kemudian, tepatnya pada 29 April 1999, terminal ini diprivatisasi dengan kepemilikan saham PT. (Persero) Pelabuhan Indonesia III sebesar 51\% dan $49 \%$ sisanya merupakan milik P\&O Ports Australia. saham yang dimiliki oleh P\&O Ports Australia diambil alih oleh Dubai Ports World (DP World) pada tahun 2006. 
Lokasi yang sangat strategis, karena secara langsung berhubungan dengan jalan raya tol Surabaya dan jalur kereta api, menjadikan terminal ini mendapatkan julukan sebagai "Pintu Gerbang ke Kawasan Indonesia Bagian Timur". Lokasinya, jika dilihat secara geografis, berada di bagian barat Pelabuhan Tanjung Perak dengan koordinat $7 ; 12 ; \mathrm{S}$, $112 ; 40 \mathrm{E}$, di bagian ujung alur pelayaran di antara pulau Jawa dan pulau Madura sepanjang 25 mil. Lebar minimum alur adalah 80 meter, kedalaman minimum pada saat air surut adalah 9.5 meter. Alur pelayaran tersebut ditandai dengan jelas, dan disediakan layanan terpadu selama 24 jam nonstop.

Terminal bongkar-muat petikemas ini memiliki beberapa standar yang dikenal dengan nama Fatal Risk Standard. Fatal Risk Standard berisikan tujuh risiko utama yang harus dikendalikan di perusahaan tersebut. Ketujuh risiko tersebut adalah keselamatan pejalan kaki (pedestrian safety), alat bergerak (mobile equipment), menangani muatan (handling load), bekerja di ketinggian (working at height), keselamatan kapal (vessel safety), teknik (engineering), dan isolasi (isolation).

\section{Gangguan Tidur yang Dialami Pekerja Shift}

Gangguan tidur merupakan salah satu efek kesehatan dan keselamatan yang dapat terjadi pada pekerja shift. Hasil identifikasi gangguan tidur yang dialami oleh para pekerja shift disajikan pada tabel 1.

Berdasarkan tabel 1, dapat diketahui bahwa dari 82 responden penelitian, sebanyak 36 responden atau 43,9\% mengalami gangguan tidur. Kesulitan untuk tidur terlebih dahulu di rumah masing-masing sebelum pergi bekerja, sebelum dan setelah bekerja di tempat kerja, serta setelah berada kembali di

Tabel 1. Distribusi Gangguan Tidur yang Dialami oleh Pekerja Shift di Terminal BongkarMuat Petikemas Tahun 2017

\begin{tabular}{lcc}
\hline \multicolumn{1}{c}{ Gangguan Tidur } & \multicolumn{2}{c}{ Jumlah } \\
\hline \multirow{2}{*}{ Ya } & $\mathrm{N}$ & 36 \\
\cline { 2 - 3 } & $\%$ & 43,9 \\
\hline \multirow{2}{*}{ Kadang } & $\mathrm{N}$ & 14 \\
\cline { 2 - 3 } Tidak & $\%$ & 17,1 \\
\hline \multirow{2}{*}{ Total } & $\mathrm{N}$ & 32 \\
\cline { 2 - 3 } & $\%$ & 39 \\
\hline
\end{tabular}

rumah merupakan beberapa alasan dari gangguan tidur yang dialami oleh para pekerja shift.

Jam kerja malam hari di terminal ini dimulai pada pukul 00.00 hingga 08.00. Jika seorang pekerja shift, dalam hal ini operator (baik CC maupun RTG) telah bekerja pada pukul 00.00 04.00, maka setelahnya ia akan digantikan oleh temannya untuk meneruskan pekerjaan tadi hingga pukul 08.00. Operator yang digantikan selanjutnya akan beristirahat di ruangan khusus yang disediakan oleh pihak manajemen, sedangkan operator yang menggantikan tadi sebelumnya harus beristirahat terlebih dahulu di ruangan yang sama. Adapun ruangan khusus untuk beristirahat para operator ini dilengkapi dengan beberapa sarana dan prasarana yang mendukung, seperti AC, TV, matras, dan lemari loker untuk menyimpan barang pribadi dan APD.

Kesulitan tidur yang dialami oleh para pekerja shift diakibatkan oleh beberapa hal. Pertama, sebelum pergi bekerja, ada beberapa pekerja yang harus melakukan dan menyelesaikan kegiatan tertentu sebelum pergi berangkat untuk bekerja shift malam. Kedua, ada beberapa pekerja shift yang tidak terbiasa untuk tidur terlebih dahulu sebelum berangkat bekerja, namun jam tidur tersebut akan ditambahkan pada jam tidur setelah pekerja shift tersebut tiba di rumah. Ketiga, adanya polusi suara yang berasal dari lingkungan kerja di sekitar ruangan khusus untuk beristirahat, seperti suara dari Head Truck yang lewat, suara alarm Container Crane pada saat berpindah tempat, suara ketika Container Crane menempatkan petikemas, juga suara yang berasal dari teman sesama operator yang tidak tidur namun memilih untuk mengobrol atau menonton TV. Terakhir, pekerja shift tidak bisa tidur lantaran ketika tiba di rumah pada pagi hari, mereka harus membantu pekerjaan rumah yang menjadi tanggung jawab mereka, seperti mengantar dan menjemput anak ke sekolah. Selain itu, aktivitas-aktivitas yang terjadi di dalam dan di luar rumah menghasilkan suara-suara yang mempersulit mereka untuk bisa tidur dengan nyenyak.

\section{Kecelakaan Kerja pada Malam Hari}

Data sekunder mengenai kecelakaan kerja pada shift malam di terminal bongkar-muat petikemas menunjukkan bahwa selama tahun 2015, telah terjadi kecelakaan kerja pada shift malam sebanyak 47 kejadian $(24,6 \%)$ dari 191 kejadian. Adapun pada tahun 2016 juga terjadi 47 kecelakaan pada shift malam (27,8\%) dari 169 kejadian. Jumlah kecelakaan kerja secara keseluruhan mengalami 
penurunan dari tahun 2015 hingga 2016, namun tidak dengan kecelakaan kerja pada shift malam.

Terminal bongkar-muat petikemas ini membagi pekerjanya menjadi tiga jenis, yakni pekerja tetap, kontraktor, dan $3^{r d}$ party. Sepanjang tahun 2015, dari 47 kejadian, sebanyak 29 pekerja tetap terminal bongkar-muat petikemas terlibat dalam kecelakaan kerja pada malam hari $(61,7 \%)$, sedangkan pada tahun selanjutnya, sebanyak 25 pekerja tetap $(53,2 \%)$ terlibat dalam kecelakaan kerja pada malam hari.

Pekerja tetap yang terlibat dalam kecelakaan kerja pada malam hari adalah operator $\mathrm{CC}$, operator RTG dan supervisor dermaga. Sebanyak 26 operator CC $(89,7 \%)$ dan tiga operator RTG $(10,3 \%)$ terlibat dalam kecelakaan kerja pada malam hari selama tahun 2015. Dari 27 pekerja tetap yang terlibat kecelakaan kerja pada malam hari di tahun 2016, sebanyak dua orang merupakan supervisor dermaga (8\%), operator CC sebanyak 18 pekerja (72\%), dan lima operator RTG $(20 \%)$.

Berdasarkan data sekunder yang telah dijelaskan sebelumnya, maka selanjutnya sasaran penelitian ini adalah pekerja shift dengan jenis pekerjaan Operator CC dan Operator RTG. Dari hasil kuesioner yang disebarkan, jenis pekerjaan yang mengalami kecelakaan kerja adalah Operator CC dengan jumlah 35 pekerja $(85,4 \%)$, sedangkan enam pekerja sisanya (14,6\%) merupakan Operator RTG.

\section{Hubungan Gangguan Tidur yang Dialami oleh Pekerja Shift dengan Kecelakaan Kerja pada Malam Hari}

Gangguan tidur yang dialami oleh pekerja shift dapat menurunkan konsentrasi pada saat bekerja, dan akibat terburuknya adalah dapat menyebabkan kecelakaan kerja. Hasil tabulasi silang antara gangguan tidur yang dialami oleh pekerja shift dengan kejadian kecelakaan kerja yang mereka alami pada tabel 2 .

Berdasarkan Tabel 2, jumlah pekerja shift yang mengalami kecelakaan kerja pada malam hari serta mengalami gangguan tidur yaitu 24 pekerja shift (29,3\%), sedangkan jumlah pekerja shift yang mengalami kecelakaan kerja pada malam hari dan tidak mengalami gangguan tidur yakni sebanyak 12 pekerja shift $(14,6 \%)$.

Pengujian statistika dilakukan menggunakan Uji Chi-Square untuk kedua variabel. Dari hasil uji yang dilakukan, didapatkan siginifikansi $P h i$ \& Cramer's $V$ sebesar 0,0014. Dengan nilai $\alpha=$ 0,05 (5\%), maka nilai signifikansi Phi \& Cramer's $V$ lebih kecil dari $\alpha$, sehingga dapat disimpulkan
Tabel 2. Distribusi Gangguan Tidur yang Dialami oleh Pekerja Shift dengan Kejadian Kecelakaan Kerja pada Malam Hari di Terminal Bongkar-Muat Petikemas Tahun 2017

\begin{tabular}{|c|c|c|c|c|c|c|}
\hline \multirow{3}{*}{$\begin{array}{l}\text { Gangguan } \\
\text { Tidur }\end{array}$} & \multicolumn{4}{|c|}{$\begin{array}{l}\text { Kecelakaan Kerja } \\
\text { pada Malam Hari }\end{array}$} & \multirow{2}{*}{\multicolumn{2}{|c|}{ Total }} \\
\hline & \multicolumn{2}{|c|}{ Ya } & \multicolumn{2}{|c|}{ Tidak } & & \\
\hline & n & $\%$ & $\mathrm{n}$ & $\%$ & $\mathbf{N}$ & $\%$ \\
\hline Ya & 24 & 29,3 & 12 & 14,6 & 36 & 43,9 \\
\hline Kadang & 7 & 8,5 & 7 & 8,5 & 14 & 17,1 \\
\hline Tidak & 10 & 12,2 & 22 & 26,9 & 32 & 39 \\
\hline Total & 41 & 50 & 41 & 50 & 82 & 100 \\
\hline
\end{tabular}

bahwa ada hubungan antara gangguan tidur yang dialami pekerja shift dengan kejadian kecelakaan kerja pada malam hari di terminal bongkar-muat petikemas. Besar hubungan antara kedua variabel tersebut adalah 0,322 .

\section{PEMBAHASAN}

\section{Gangguan Tidur yang Dialami Pekerja Shift}

Suprachiasmatic Nucleus (SCN) merupakan kumpulan dari ujung-ujung syaraf yang terletak di Hypothalamus. SCN ini bertugas untuk mengatur jam biologis setiap organ manusia agar dapat terhubung satu sama lain dengan baik. Jam biologis inilah yang mempengaruhi ritme sirkadian dalam tubuh manusia. Perubahan pada keadaan fisik, mental dan perilaku yang mengikuti perjalanan jam dalam sehari disebut ritme sirkadian.

Ritme ini dihasilkan dari aktivitas-aktivitas genetik yang terjadi di dalam tubuh dan terpengaruh dengan hal-hal yang berasal dari luar tubuh manusia, seperti cahaya dari lingkungan sekitar. Cahaya dari luar mampu mengatur gen-gen di dalam tubuh yang bertanggung jawab dalam pengaturan jam internal tubuh. Fungsi terpenting dari ritme sirkadian ini adalah menentukan pola tidur dari manusia itu sendiri. Mekanisme pengaturan pola tidur tersebut dimulai ketika SCN mengirimkan informasi kepada otak untuk menghasilkan Melatonin ketika manusia berada pada area yang minim cahaya dan menyebabkan rasa kantuk datang.

Berdasarkan paparan yang dijabarkan oleh Health and Safety Authority pada tahun 2012 tersebut, maka dapat dikatakan bahwa pekerjaan 
shift malam dapat menyebabkan gangguan pada ritme sirkadian. Hal ini dikarenakan ketika pada malam hari yang merupakan waktu istirahat, tubuh pekerja shift malam tidak bisa memenuhi tuntutan tersebut lantaran harus melaksanakan pekerjaan. Begitu juga sebaliknya, ketika pada pagi hari pekerja shift malam akan beristirahat, tubuhnya tidak akan mampu beristirahat dengan maksimal lantaran adanya paparan cahaya dari lingkungan sekitarnya.

Terganggunya tidur dapat menjadi penyebab penting untuk terjadinya efek kesehatan jangka panjang dari shift kerja dan shift malam. Penelitian epidemiologi jangka panjang yang dilakukan pada populasi normal dan pekerja shift menunjukkan bahwa terganggunya atau memendeknya jam tidur tidak hanya dapat memperkirakan jumlah absensi akibat sakit, stress yang berkaitan dengan pekerjaan, maupun burn out (perasaan kegagalan dan kelesuan akibat tuntutan yang terlalu membebankan tenaga dan kemampuan seseorang), namun juga beberapa penyakit lainnya seperti obesitas dan diabetes tipe II, penyakit jantung koroner dan infark pada otak, MSDs, depresi, dan masalah-masalah penyakit jiwa yang minor (Härmä, dkk., 2008)

Berdasarkan kriteria klinis dari DSM-IV, $10 \%$ dari pekerja shift dan shift malam memiliki gangguan yang disebut shift-work sleep disorder (Härmä, dkk., 2008). Secara umum telah diketahui bahwa prevalensi dari rasa kantuk yang berlebihan pada saat bekerja (menunjukkan gejala kekacauan pada kualitas tidur) adalah sebanyak $25 \%$, dan jika ditambah dengan penurunan kewaspadaan maka akan menambah prevalensi sebanyak 50\%. Secara kasar, dapat dikatakan bahwa perkiraan proporsi pekerja shift dengan penurunan kualitas tidur atau kewaspadaan yang parah berada pada angka diatas 50\% (Härmä, dkk., 2008). Adapun gangguan tidur akibat shift kerja akan meningkat seiring dengan proses penuaan (Härmä, dkk., 2008).

\section{Kecelakaan Kerja pada Malam Hari}

Rasa kantuk utamanya akan menjadi bertambah parah pada saat shift malam, sedangkan pada shift sore rasa kantuk susah untuk muncul dan pada shift pagi rasa kantuk berada pada tingkat sedang. Tingkatan rasa kantuk terberat muncul ketika jam kerja mulai memasuki jam-jam awal dari pagi hari, yakni pada pukul 05.00-07.00. Rekaman Electroencephalographic menunjukkan bahwa kejadian tertidur pada saat bekerja pada malam hari benar-benar terjadi pada beberapa jenis pekerjaan, seperti operator proses masinis supir truk mahasiswa kedokteran yang sedang melakukan magang dan pilot (Åkerstedt, 2006). Semua penelitian tersebut menunjukkan tanda-tanda yang jelas dari kejadian tertidur secara tiba-tiba selama bekerja pada malam hari. Pada berbagai kasus, telah banyak bukti yang menyatakan bahwa rasa kantuk akibat bekerja pada malam hari memiliki hubungan dengan peningkatan kelelahan dan menjadi risiko keselamatan pada beberapa pekerjaan ( $\AA$ kerstedt, 2006).

Dalam kajian lima studi mereka, Folkard dan Tucker (2003) menyimpulkan bahwa risiko cedera meningkat $18 \%$ pada shift siang hari dan $30 \%$ pada shift malam dibandingkan dengan shift pagi. Dari lima penelitian tersebut, hanya dalam jurnal Salminen (2010) serta Smith et al. (1994), menuliskan sistem shift yang digunakan oleh perusahaan tempat penelitian mereka, yakni menggunakan sistem tiga shift yang berputar. Selain itu, berdasarkan tujuh penelitian, Folkard dan Tucker (2003) menghitung bahwa risiko cedera $6 \%$ lebih tinggi pada malam kedua, $17 \%$ lebih tinggi pada malam ketiga, dan 30\% lebih tinggi pada malam keempat. Di sisi lain, lima dari tujuh penelitian ini menunjukkan bahwa risiko cedera $2 \%$ lebih tinggi pada shift pagi kedua, 7\% pada shift pagi ketiga, dan 17\% lebih tinggi pada shift pagi keempat. Berdasarkan 10 penelitian, Folkard dan Åkerstedt (2004) telah menghitung bahwa selama malam hari, risiko cedera naik $20 \%$ dari jam pertama sampai jam kedua, kemudian turun sekitar 50\% mencapai minimum pada akhir shift. Namun, ada sedikit peningkatan risiko cedera antara pukul 03:00 dan 04:00 (Härmä, 2008).

Analisis kecelakaan kerja fatal yang terjadi di Australia pada tahun 1982 hingga 1984 menunjukkan bahwa selama shift malam jumlah korban jiwa menjadi dua kali lipat dibandingkan dengan jumlah pekerja pada shift tersebut. Sebagian besar kejadian dengan korban jiwa terjadi pada pagi sampai sore hari, dan paling sedikit antara pukul 23.00 dan 01.00 malam, lalu mengalami penurunan lebih lanjut pada pukul 04.00. Risiko terjadinya kesalahan akibat manusia (human error) terbesar ada pada pagi hari antara pukul 00.00 dan 06.00 (Härmä, 2008).

\section{Hubungan Gangguan Tidur yang Dialami oleh Pekerja Shift dengan Kecelakaan Kerja pada Malam Hari}

Claire (2014) dalam jurnalnya menuliskan bahwa terdapat bukti secara ilmiah yang kuat terhadap hubungan antara masalah atau gangguan tidur dan shift kerja. Hasil penelitian yang dilakukan 
pada sekelompok sampel pekerja shift di Timur Tengah menunjukkan bahwa sebanyak $26 \%$ dari pekerja shift yang berotasi (rotating-shift workers) dilaporkan memiliki insomnia jangka panjang dan rasa kantuk yang berlebihan (Claire, 2014).

Härmä (2008) menjelaskan bahwa ada beberapa faktor yang mempengaruhi kondisi tertidur dan terjaganya pekerja pada saat bekerja. Pertama adalah ritme sirkadian. Ritme sirkadian memiliki hubungan dan pengaruh dalam siklus tidur dan terjaga dalam pekerjaan yang dilakukan dengan shift. Tidur malam sebelum shift pagi yang dimulai lebih awal dan tidur siang setelah shift malam biasanya dibatasi hanya beberapa jam saja (Härmä, 2008). Rasa kantuk paling sering terjadi pada malam hari dan shift pagi yang sangat awal (Härmä, 2008). Adapun rasa kantuk yang parah dilaporkan terjadi pada $49 \%$ shift malam dan pada $20 \%$ pada shift pagi yang dimulai lebih awal pada sekelompok besar pengemudi kereta api atau masinis (Härmä, 2008). Pada siang hari dan shift sore, rasa kantuk yang parah jarang terjadi. Rasio menunjukkan bahwa risiko kantuk yang parah adalah 6-14 kali lebih tinggi pada shift malam dan sekitar dua kali lebih tinggi pada shift pagi dibandingkan dengan shift siang (Härmä, 2008).

Faktor selanjutnya adalah waktu yang dihabiskan untuk terbangun. Rasa kantuk meningkat pada shift malam pertama di tempat kerja akibat pengaruh ritme sirkadian, karena waktu yang dihabiskan jauh lebih singkat selama siang hari dan bahkan pada shift sore jika dibandingkan dengan shift malam pertama kalinya. Selama shift malam pertama, rasa kantuk bisa menjadi lebih tinggi dibanding shift malam kedua atau ketiga karena waktu terbangun atau terjaga yang dihabiskan lebih lama sebelum shift malam. Sekitar $50-80 \%$ pekerja shift melakukan tidur siang sebelum shift malam pertama (Härmä, 2008). Pilihan untuk tidur siang sebelum atau selama melakukan shift malam sangat penting untuk mempengaruhi rasa kantuk saat shift malam, karena akan memberikan pengaruh pada peningkatan kewaspadaan dan kinerja secara signifikan (Härmä, 2008). Sistem shift sangat bervariasi dalam memberikan pengaruh terhadap waktu yang digunakan untuk terjaga dan pemulihan tidur. Terlalu pendeknya selang waktu antara shift malam dan shift pagi menurunkan lama waktu untuk tidur dan dapat membuat pemulihan waktu tidur menjadi tidak tercukupi. Waktu dimulainya shift pagi sangat penting, karena setiap penundaan satu jam pada waktu dimulainya shift pagi, akan menyebabkan penambahan 40-50 menit pada waktu tidur utama (Härmä, 2008). Manusia membutuhkan sekitar 8 jam untuk tidur per hari, dan jika waktu malam hari antara dua shift kurang, maka dapat dikatakan dengan jelas bahwa pemulihan penuh dalam waktu tidur tidak mungkin dilakukan.

Faktor ketiga adalah tuntutan kerja. Tuntutan dan tugas-tugas dari pekerjaan dapat mengubah rasa kantuk dengan variasi beban kerja mental dan fisik yang diberikan, atau variasi dari faktor monoton, stres, lingkungan dan ergonomi (suhu, getaran, kebisingan, posisi kerja yang berbeda). Interaksi antara kekurangan waktu tidur dengan tuntutan kerja telah diteliti pada shift kerja dengan 12 jam kerja. Berdasarkan rasa kantuk objektif yang direkam terus-menerus dengan menggunakan EEG/ EOG selama masa kerja, hasilnya menunjukkan bahwa tugas pekerjaan yang bersifat monoton akan meningkatkan rasa kantuk pada siang hari seperti pada tingkat kekurangan tidur level sedang (Härmä, 2008). Adapun tekanan psikososial, yang diukur dengan model Karasek, juga berkorelasi kuat dengan tidur dan rasa kantuk di tempat kerja (Härmä, 2008). Mengenai faktor lingkungan, ternyata suhu yang lebih tinggi akan meningkatkan rasa kantuk di tempat kerja, sedangkan paparan cahaya terang akan menurunkan rasa kantuk.

Faktor terakhir adalah perbedaan karakteristik individu dari para pekerja. Manifestasi tidur dan rasa kantuk dalam jam kerja yang tidak normal sangat berbeda untuk setiap individu (Härmä, 2008). Persentase populasi pekerja yang gagal menyesuaikan diri dengan pekerjaan shift diperkirakan sekitar 10-20\%. Penuaan adalah salah satu faktor utama yang mempengaruhi penyesuaian ritme sirkadian untuk pekerjaan yang dilakukan pada malam hari (Härmä, 2008) dan fungsi homeostatis tidur (Härmä, 2008). Penuaan berhubungan dengan melambatnya penyesuaian ritme sirkadian pada saat melakukan shift malam berturut-turut, serta membuat jam tidur setelah shift malam menjadi lebih pendek (Härmä, 2008). Studi epidemiologi menunjukkan bahwa insomnia akibat bekerja shift meningkat seiring dengan pertambahan usia pekerja (Härmä, 2008). Pekerja shift dengan usia yang lebih tua tidak mengeluhkan rasa kantuk lebih berat jika dibandingkan dengan rekan kerja yang lebih muda (Härmä, 2008).

Efek akibat bekerja pada malam hari dan shift kerja pada kualitas dan kuantitas tidur serta kelelahan dimodifikasi oleh beberapa faktor yang berbeda, seperti tipe diurnal, kepribadian, dan mekanisme koping yang berbeda (seperti aktivitas 
fisik) pada masing-masing pekerja (Härmä, 2008). Dalam sebuah studi intervensi yang dikendalikan, aktivitas fisik yang dilakukan secara teratur dapat meningkatkan kualitas tidur secara umum, dan juga kewaspadaan terutama selama shift malam pada perawat dalam sistem shift yang tidak teratur (Härmä, 2008).

Tidur siang yang dijadwalkan untuk pekerja shift mungkin berguna dalam mengurangi rasa kantuk yang berlebihan selama shift kerja. Konfigurasi durasi tidur siang yang tepat agar dapat memaksimalkan kewaspadaan dalam bekerja belum dapat ditemukan. Tidur selama 20 sampai 40 menit pada saat shift malam (misalnya antara jam 2 hingga 3 pagi) nyatanya memiliki manfaat selayaknya tidur siang yang dilakukan sebelum shift malam (Rajaratnam, et al., 2013). Potensi gangguan kewaspadaan akibat sleep-inertia, juga waktu yang dibutuhkan untuk mengatasinya harus dipertimbangkan, terutama untuk tidur siang yang terjadi selama shift kerja. Sleep-inertia mengacu pada penurunan yang terjadi sesaat setelah terbangun dan bisa berlangsung beberapa menit, bahkan hingga beberapa jam. Besarnya penurunan bahkan mungkin lebih buruk daripada setelah 24 jam kurang tidur. Penelitian mengenai shift kerja dengan sistem simulasi yang dilakukan di laboratorium dengan responden laki-laki yang sehat menunjukkan bahwa interval 15 menit untuk mengatasi sleep-inertia harus dilakukan setelah tidur siang selama 60 menit. Kesimpulan lain dari penelitian ini adalah perasaan mengantuk yang subjektif bukanlah indikator yang dapat digunakan untuk gangguan kinerja akibat sleep-inertia (Rajaratnam, et al., 2013).

Sejalan dengan pernyataan di atas, Åkerstedt (2006) menyatakan bahwa ada beberapa cara untuk menanggulangi gangguan tidur yang dialami oleh para pekerja shift. Tidur di siang hari merupakan tindakan penanggulangan paling alami terhadap rasa kantuk, dan hasil penelitian yang dilakukan dengan cara melakukan simulasi bekerja pada malam hari menyimpulkan bahwa cara ini cukup bagus untuk diterapkan. Konsumsi kafein merupakan cara lain untuk menangkal rasa kantuk, dan kemampuannya untuk melawan rasa kantuk didokumentasikan dengan baik dalam sebuah penelitian yang melakukan simulasi kerja shift (Åkerstedt, 2006). Hasil penelitian menunjukkan bahwa konsumsi kafein untuk mengurangi rasa kantuk memiliki tingkat efektivitas yang sama dengan mengonsumsi obat modafinil dan dextroamphetamine (dalam
Åkerstedt, 2006). Dari ulasan tersebut, dapat disimpulkan bahwa upaya penanggulangan rasa kantuk yang paling baik adalah menggabungkan konsumsi kafein dengan melakukan tidur siang. Alasan untuk melakukan kombinasi kedua cara diatas adalah untuk membatasi konsumsi kafein secara berlebihan, dan juga dapat membatasi penggunaan obat-obatan seperti modafinil dan dextroamphetamine dalam jangka panjang (Åkerstedt, 2006).

\section{SIMPULAN}

Sebanyak 36 responden $(43,9 \%)$ dari 82 responden mengalami gangguan tidur sebagai akibat dari shift malam. Adapun responden terbanyak yang mengalami kecelakaan kerja adalah operator CC yakni sebanyak 35 responden $(85,4 \%)$ dari 41 responden dalam kelompok kasus. Adapun pekerja shift yang mengalami gangguan tidur dan kecelakaan kerja berjumlah 29,3\% atau sebanyak 24 pekerja, sedangkan pekerja shift yang mengalami gangguan tidur namun mengalami kecelakaan kerja berjumlah 12 pekerja $(14,6 \%)$. Hasil pengujian statistika menggunakan Uji Chi-Square menyimpulkan bahwa terdapat hubungan antara gangguan tidur pada pekerja shift dengan kejadian kecelakaan kerja pada malam hari $(0,0015<0,005)$.

\section{DAFTAR PUSTAKA}

Åkerstedt, T., 2006. Searching for the Countermeasure of Night-Shift Sleepiness. Sleep. p. 19-20. Vol. 29. No. 1. www.journalsleep.org/article. [Sitasi 16 Juli 2017] .

Australian Manufacturing Worker's Union., 2009. Health \& Safety Guidelines for Shift Work. www. amwu.org.au/Stay_Healthy_When_Working_ Shiftwork.pdf [Sitasi 27 Maret 2017].

Claire C., 2014. Negative Impacts of Shiftwork and Long Work Hours. NHS Public Access. www. ncbi.nlm.nih.gov/nihms731739.pdf [Sitasi 16 Juli 2017].

Dembe AE., Erickson JB., Delbos RG., Banks SM., 2006. Nonstandard Shift Schedules And The Risk Of Job-Related Injuries. Scandinavian Journal of Work, Environment \& Health [e-journal] 32(3): pp. 232-240. Tersedia di www.sjweh.fi/ x06_232_240.pdf [Sitasi 29 September 2016].

Department for Transport., 2005. Transport Statistics Bulletin: Port Employment and 
Accident Rates. https://www.gov.uk/uploads/file/ portemploymentandaccidentsra5175.pdf [Sitasi 09 November 2016]

Folkard, S., Tucker, P., 2003. Shift Work, Safety, and Productivity. [e-journal] Tersedia di isites. harvard.edu/Folkard_Shift_work [Sitasi 29 September 2016]

Härmä, S., Sallinen, M., Puttonen, S., Salminen, S., \& Hublin, C., 2008. Risk Factors and Risk Reduction Strategies Associated with Night Work with The Focus on Extended Work Periods and Work Time Arrangement within The Petroleum Industry in Norway. www.ptil.no/ getfile.php/Dokumenter [Sitasi 16 Juli 2017]

Health and Safety Authority, 2012. Guidance for Employers and Employees on Night and Shift Work. www.hsa.ie/eng/Occupational_Health [Sitasi 29 September 2016]

Organisation for Economic Co-Operation and Development, 2012. OECD Reviews of Regulatory Reform: Indonesia Regulatory and Competition Issues in Ports, Rail and Shipping. [pdf] Tersedia di www.oecd.org/Indonesia/Chap-5-Ports-RailAnd-Shipping [Sitasi 09 November 2016].
Peraturan Menteri Perhubungan Nomor 51 Tahun 2015 tentang Penyelenggaraan Pelabuhan Laut. Jakarta: Kementerian Perhubungan.

Rajaratnam, S., Howard, M., \& Grunsteln, R., 2013. Sleep loss and Circadian Disruption in Shift Work: Health Burden and Management. The Medical Journal of Australia. p. 511-515. www.sleephealthfoundation.org.au/files/MJA Supplement/MJA [Sitasi 05 Juli 2017].

Salminen, S., 2010. Shift Work and Extended Working Hours as Risk Factors for Occupational Injury. The Ergonomics Open Journal. p. 14-18. bentham-open.com/pdf/TOERGJ-3-14 [Sitasi 01 November 2016].

Smith L., Folkard S., Poole CJM., 1994. Increased Injuries On Night Shift. Lancet [e-journal] 344: pp. 1137-1139. Tersedia di https://www. researchgate.net/publication/15263736 Increased_injuries_on_night_shift [Sitasi 29 September 2016].

Steenken, D, VOB, S \& Stahlbock, R., 2004. Container Terminal Operation and Operations Research: A Classification and Literature Review. OR Spectrum. p. 3-49. https://www.researchgate. net/publication [Sitasi 09 November 2016]. 